\title{
Zinc Alters Excitatory Amino Acid Neurotoxicity on Cortical Neurons
}

\author{
Jae-young Koh and Dennis W. Choi \\ Department of Neurology, Stanford University Medical Center, Stanford, California 94305
}

Recent studies have suggested that large amounts of free zinc may be coreleased during excitatory synaptic transmission at glutamatergic synapses, and may act postsynaptically to decrease actions mediated by $\mathbf{N}$-methyl-D-aspartate (NMDA) receptors, while often increasing neuroexcitation mediated by quisqualate receptors. The present study examined the ability of zinc to alter excitatory amino acid (EAA) neurotoxicity. Murine cortical cell cultures were exposed to EAAs for 5 min in defined solutions, and neuronal cell injury was examined the following day both morphologically and by lactate dehydrogenase assay. Inclusion of 30-500 $\mu \mathrm{M}$ zinc in the exposure solution produced a zinc concentration-dependent, noncompetitive attenuation of NMDA-induced neuronal injury, with an $E D_{50}$ of about $80 \mu \mathrm{M}$. In contrast, zinc produced the same concentration-dependent potentiation of quisqualate neurotoxicity; and with $500 \mu \mathrm{M}$ zinc, a small potentiation of kainate neurotoxicity was suggested. The effect of zinc on the neurotoxicity of the broad-spectrum agonist glutamate was consistent with these effects on specific agonists, as well as with a previous study showing that glutamate neurotoxicity normally depends predominantly on NMDA-receptor activation. Zinc produced a concentrationdependent reduction in glutamate-induced neuronal injury in a fashion similar to that seen with NMDA, but less effectively. In addition, despite this overall protective effect, zinc paradoxically increased the glutamate-induced destruction of nicotinamide adenine dinucleotide phosphate diaphorase (NADPH-d)-containing neurons, a subpopulation that was shown in the preceding paper (Koh and Choi, 1988) to exhibit resistance to NMDA receptor-mediated neurotoxicity, and vulnerability to non-NMDA receptor-mediated neurotoxicity. This selective destruction was not produced by several other NMDA antagonists, including magnesium.

These data indicate that endogenous zinc, at concentrations that may be realized during pathophysiological conditions, could importantly alter the neurotoxicity of endogenous glutamate or related EAAs, reducing NMDA receptor-mediated injury while increasing quisqualate (and perhaps kainate) receptor-mediated injury.

Several investigators have now postulated that the release of glutamate (and related compounds) at central excitatory synapses may commonly be accompanied by the corelease of substantial amounts of free zinc ( $\mathrm{Zn}$ ). Mammalian brain, especially

\footnotetext{
Received July 20, 1987; revised Oct. 19, 1987; accepted Oct. 20, 1987.

We thank M. P. Goldberg and S. Peters for helpful discussions, and V. Viseskul for expert assistance with cell cultures. This research was supported by NIH Grants NS21628 and NS12151, and by a Hartford Fellowship (to D.W.C.) from the John A. Hartford Foundation.

Correspondence should be addressed to Dennis W. Choi, Department of Neurology, C-338, Stanford University Medical Center, Stanford, CA 94305.

Copyright (C) 1988 Society for Neuroscience $0270-6474 / 88 / 062164-08 \$ 02.00 / 0$
}

neocortex, pineal, and hippocampus (Wong and Fritze, 1969; Donaldson et al., 1973; Frederickson et al., 1982), contains considerable amounts of $\mathrm{Zn}$. While $\mathrm{Zn}$ is likely a cofactor in myriad metabolic processes (Vallee, 1959), histochemical methods have revealed foci of chelatable $\mathrm{Zn}$ (Danscher et al., 1985), specifically in forebrain neuropil (Haug, 1973), and ultrastructural studies have further suggested that much of this $\mathrm{Zn}$ is located within certain synaptic vesicles in excitatory synaptic boutons (Ibata and Otsuka, 1969; Perez-Clausell and Danscher, 1985). Release of endogenous $\mathrm{Zn}$ to the extracellular space appears to occur spontaneously (Charton et al., 1985; Perez-Clausell and Danscher, 1986), and has been shown to be increased in a calcium-dependent fashion by either high-potassium or electrical stimulation (Assaf and Chung, 1984; Howell et al., 1984; Aniksztejn et al., 1987).

The function of such synaptically relcascd $\mathrm{Zn}$ is at present unknown, although some participation in excitatory neurotransmission seems probable. Recently, we reported that $\mathrm{Zn}$ could selectively attenuate $N$-methyl-D-aspartate (NMDA) receptormediated excitation of cortical neurons, while producing some potentiation of quisqualate receptor-mediated excitation (Peters et al., 1987). On the basis of this finding, we proposed that the corelease of $\mathrm{Zn}$ with glutamate at central excitatory synapses may normally serve to modulate the distribuion of receptor subtypes activated by glutamate, decreasing the activation of NMDA receptors while increasing the activation of quisqualate receptors.

If indeed $\mathrm{Zn}$ is coreleased with synaptically released glutamate, it might not only modify the postsynaptic effects of glutamate during the brief exposures associated with normal synaptic transmission, but it could also importantly modify the neurotoxicity of extracellular glutamate during the prolonged exposures thought to occur in certain disease states (Rothman and Olney, 1987). Glutamate neurotoxicity, as modified by $\mathrm{Zn}$, could be highly relevant to the pathophysiology of neuronal loss in these disease states-in some brain regions, perhaps more directly than glutamate neurotoxicity alone.

We have previously reported that $\mathrm{Zn}$ could selectively attenuate NMDA-induced cortical neuronal damage (Peters et al., 1987). The purpose of the present study was to extend that observation, characterizing in greater detail the effect of $\mathrm{Zn}$ on EAA neurotoxicity. On the basis of the preceding study of the selective vulnerability of NADPH-d-containing [NADPH-d(+)] neurons (Koh and Choi, 1988), we utilized the fate of this special subpopulation as an assay for distinguishing NMDA receptormediated neurotoxicity from non-NMDA receptor-mediated neurotoxicity.

\section{Methods}

Methods for cortical cell culture, 5 min exposure to EAAs, NADPH-d histology, and assessment of neuronal cell injury were as described in the preceding paper (Koh and Choi, 1988). 
Zn BLOCKS NMDA NEUROTOXICITY

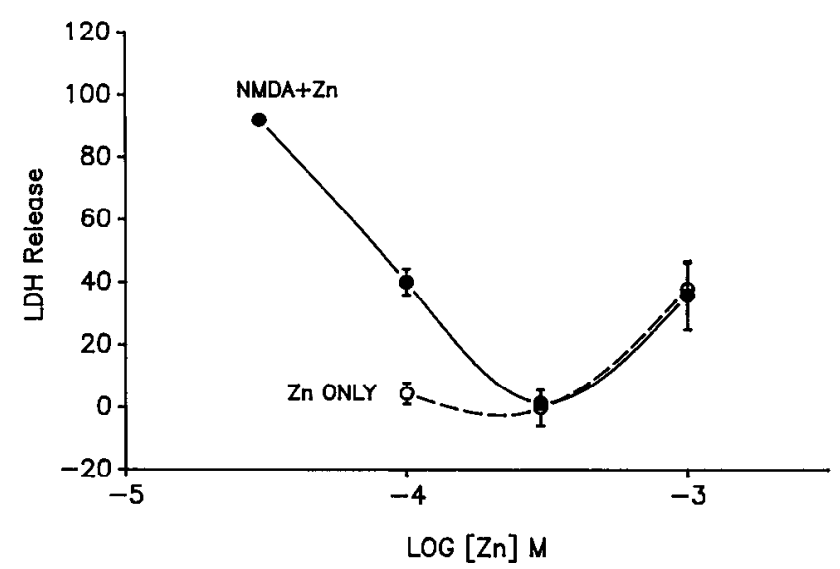

Figure 1. Zn blocks NMDA neurotoxicity in a concentration-dependent manner. Closed circles show LDH efflux (mean and SEM, $n=4$ ) to the bathing medium in a set of matched sister cultures exposed to $500 \mu \mathrm{M}$ NMDA for $5 \mathrm{~min}$, with the indicated concentration of $\mathrm{Zn}$ added to the exposure solution. Open circles show the same for other sister cultures exposed for $5 \mathrm{~min}$ to $\mathrm{Zn}$ alone ( $\mathrm{Zn}$ only). $\mathrm{LDH}$ values were scaled to the mean value observed in a set of matched control cultures exposed to $500 \mu \mathrm{M}$ NMDA alone for $5 \mathrm{~min}(=100)$. At $300 \mu \mathrm{M}, \mathrm{Zn}$ completely blocked both the morphological and chemical evidence of neuronal injury. At $1 \mathrm{~mm}, \mathrm{Zn}$ showed some intrinsic neurotoxicity.

$\mathrm{Zn}$ chloride (ACS reagent grade) was obtained from Sigma. Other inorganic salts were Baker reagent grade with negligible listed $\mathrm{Zn}$ contamination. Tris was obtained from Sigma (reagent grade).

The only major source of Zn known to be present in the culture media was that contributed by the sera (Hyclone Defined), producing a net $\mathrm{Zn}$ concentration of $<6 \mu \mathrm{M}$ in the plating medium, and $<2 \mu \mathrm{M}$ in the maintenance medium (estimate based on the supplier's assay of sera $\mathrm{Zn}$ concentrations). Water used to prepare the media and the exposure solutions (see below) was obtained from a Millipore Milli-Q purification system $(R>15 \mathrm{M} \Omega \mathrm{cm})$.

\section{Results}

As previously described, the widespread cortical neuronal cell loss produced by exposure to $500 \mu \mathrm{M}$ NMDA for $5 \mathrm{~min}$ could be essentially eliminated by the addition of $300 \mu \mathrm{M} \mathrm{Zn}$ to the exposure solution; neurons remained morphologically intact and excluded trypan blue dye (Peters et al., 1987). This protective effect of $\mathrm{Zn}$ was concentration-dependent, and could be quantitated by measuring the LDH released to the bathing medium by injured neurons. Thirty micromolar $\mathrm{Zn}$ produced little neuronal protection, and $100 \mu \mathrm{M} Z \mathrm{Zn}$ produced partial protection (Fig. 1). Whereas $\mathrm{Zn}$ concentrations of $300 \mu \mathrm{M}$ or less did not exhibit intrinsic neurotoxicity (with this $5 \mathrm{~min}$ exposure), $1 \mathrm{mM}$ $\mathrm{Zn}$ alone was somewhat neurotoxic (Yokoyama et al., 1987); thus the resulting $\mathrm{Zn}$ concentration-NMDA neurotoxicity relationship was $U$-shaped, with minimum net neuronal damage observed at $300 \mu \mathrm{M} \mathrm{Zn}$ (Fig. 1).

The concentration-toxicity relationship characterizing a $5 \mathrm{~min}$ exposure to NMDA was presented in the preceding paper (Koh and Choi, 1988). The selective NMDA antagonist, 2-amino-5phosphonovalerate (APV) has been previously shown to competitively antagonize NMDA-induced neuroexcitation (Davies et al., 1981; Olverman et al., 1984). If APV was added to the exposure solution, the NMDA concentration-toxicity relationship was shifted in grossly parallel fashion to the right, with little or no change in maximal neurotoxicity (Fig. 2), consistent with competitive inhibition of neurotoxicity. However, whereas

\section{EFFECT OF ANTAGONISTS ON NMDA TOXICITY}

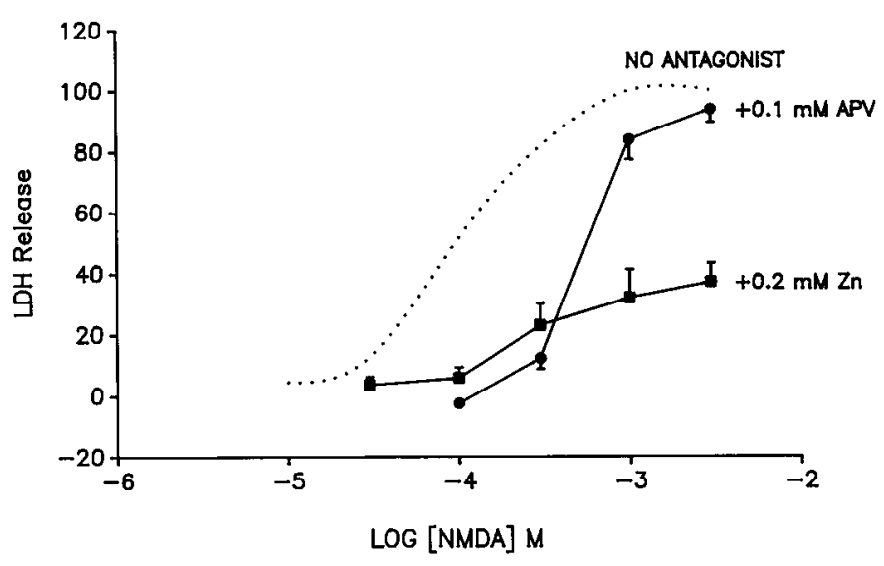

Figure 2. Zn block of NMDA neurotoxicity is noncompetitive. Concentration-toxicity relationship (mean and SEM LDH efflux, $n=4$ ) for a 5 min exposure to NMDA in the presence of $100 \mu \mathrm{M}$ APV (circles) is compared to that in the presence of $200 \mu \mathrm{M} \mathrm{Zn}$ (squares). The comparison was done on a large set of matched sister cultures; $\mathrm{LDH}$ values have been scaled to the mean value of other sister cultures exposed to $3 \mathrm{~mm}$ NMDA alone. For comparison, the dotted line shows a similarly scaled concentration-toxicity relation obtained for NMDA alone in another experiment (Koh and Choi, 1988, Fig. 5A).

the addition of $200 \mu \mathrm{M} \mathrm{Zn}$ produced less neuronal protection than $100 \mu \mathrm{M}$ APV at low ( $300 \mu \mathrm{M}$ or less) NMDA concentrations, the Zn block, unlike the APV block, was not overcome at higher NMDA concentrations (Fig. 2).

We previously reported that $\mathrm{Zn}$ not only reduced NMDA receptor-mediated neuroexicitation and neurotoxicity, but also reliably potentiated quisqualate neuroexcitation (Peters ct al., 1987). Some suggestion of potentiation of quisqualate and kainate neurotoxicity was seen (Peters et al., 1987), but those experiments were directed toward establishing the selectivity of NMDA antagonism, and employed high agonist concentrations. Under exposure conditions designed to produce only minimal amounts of quisqualate-induced neuronal injury (Koh and Choi, 1988), the addition of $500 \mu \mathrm{M} \mathrm{Zn}$ dramatically increased quisqualate-induced neuronal injury, as judged both morphologically (Fig. 3) and by lactate dehydrogenase (LDH) efflux (Fig. 4). A similar, but lesser, potentiation of low-grade kainate neurotoxicity was suggested (Figs. 3,4). Control experiments in sister cultures showed that $5 \mathrm{~min}$ exposure to $500 \mu \mathrm{M} \mathrm{Zn}$ alone was associated with little neuronal injury (Fig. 4).

The ability of $\mathrm{Zn}$ to potentiate quisqualate neurotoxicity was concentration-dependent over approximately the same concentration range ( $30 \mu \mathrm{M}$ to $1 \mathrm{mM})$ as the ability of $\mathrm{Zn}$ to attenuate NMDA neurotoxicity (Fig. 5). At concentrations approaching $1 \mathrm{mM}$, however, the emergence of intrinsic $\mathrm{Zn}$ neurotoxicity likely contributed to net neuronal injury.

Although glutamate produces its neuroexcitatory effects on cortical neurons by activating both NMDA and non-NMDA receptors (Watkins and Evans, 1981), previous experiments have shown that the neurotoxicity of brief glutamate exposure on cortical neurons depends predominantly on activation of the former (Choi et al., 1988). The prediction that $\mathrm{Zn}$ might therefore attenuate the net neuronal loss produced by glutamate was tested directly. Cortical cultures exposed to $500 \mu \mathrm{M}$ glutamate for $5 \mathrm{~min}$ showed, as expected (Choi et al., 1987a), progressive neuronal disintegration over the following day (Fig. 6A). If 300 

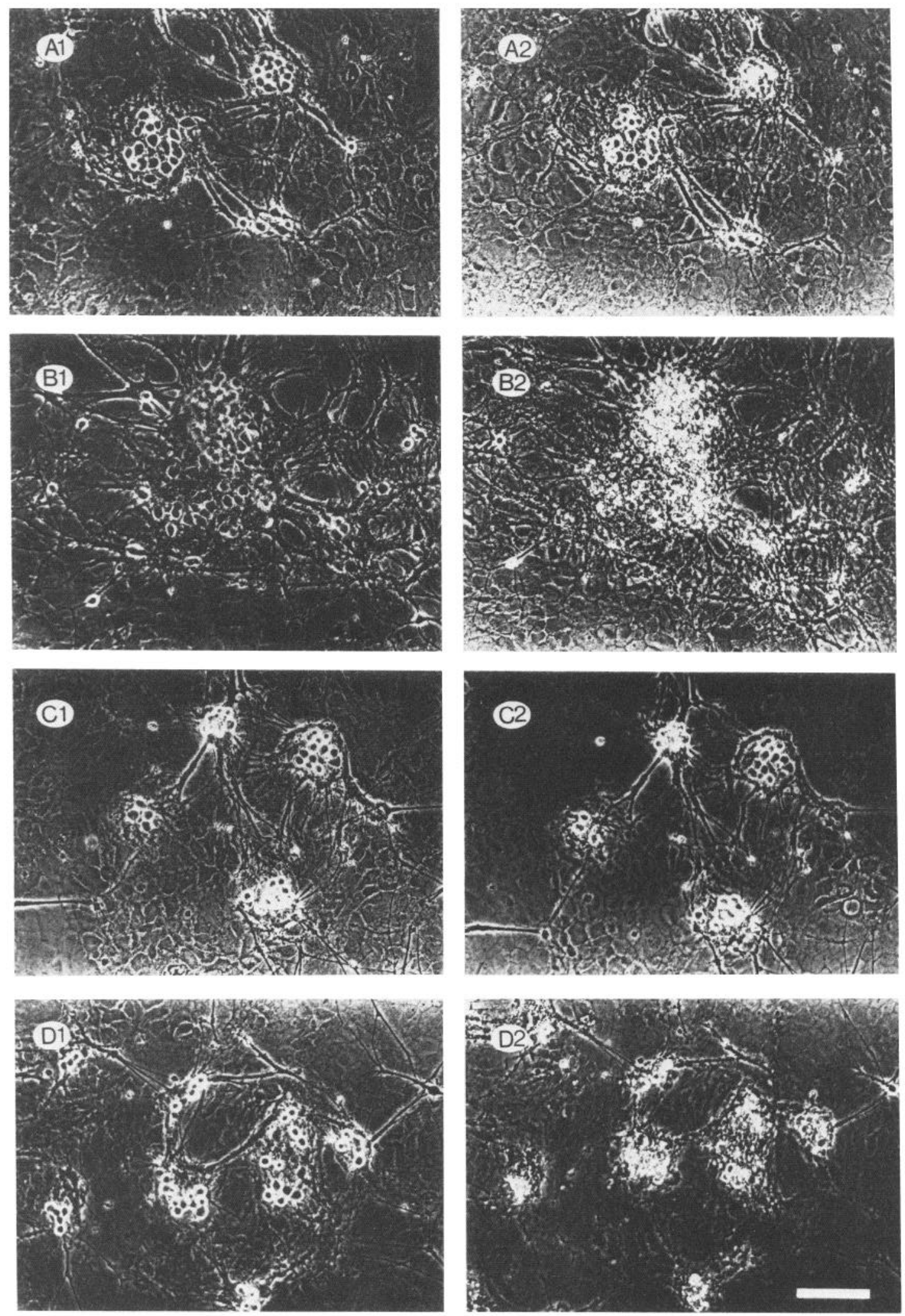

Figure 3. Morphological evidence for $\mathrm{Zn}$ potentiation of non-NMDA neurotoxicity. Phase-contrast photomicrographs of identified fields before (left) and $1 \mathrm{~d}$ after (right) a $5 \mathrm{~min}$ exposure to the following: $A, 30 \mu \mathrm{M}$ quisqualate; $B, 30 \mu \mathrm{M}$ quisqualate and $500 \mu \mathrm{M} \mathrm{Zn} ; C$, $1000 \mu \mathrm{M}$ kainate; or $D, 1000 \mu \mathrm{M}$ kainate and $500 \mu \mathrm{M} \mathrm{Zn}$. The addition of $\mathrm{Zn}$ increased the small amount of damage associated with these exposures to quisqualate or kainate. Sister cultures exposed to $500 \mu \mathrm{M} \mathrm{Zn}$ alone did not show noticeable damage (not shown). Bar, $100 \mu \mathrm{m}$. 
EFFECT OF Zn ON NEUROTOXICITY

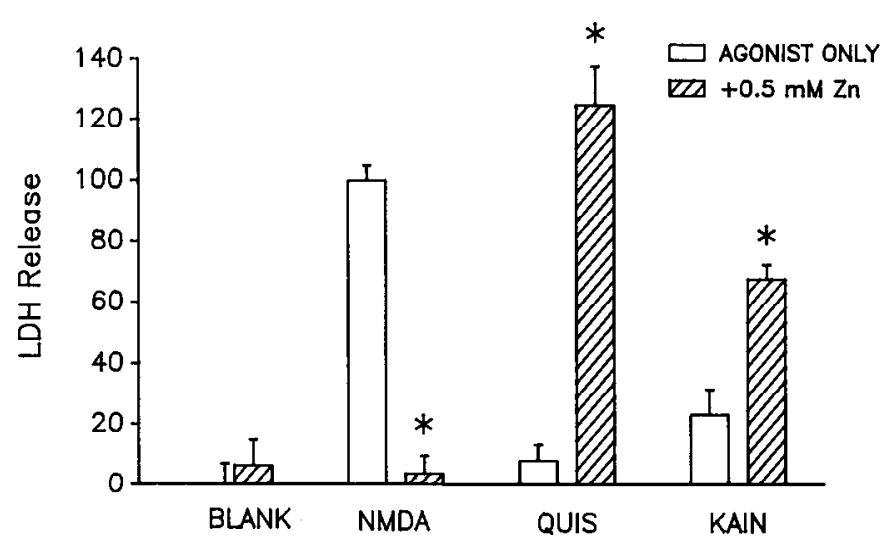

Figure 4. Chemical evidence for $\mathrm{Zn}$ potentiation of non-NMDA neurotoxicity. Bars depict the mean $\pm \operatorname{SEM}(n=5$ or 6$) \mathrm{LDH}$ in the medium $1 \mathrm{~d}$ after a $5 \mathrm{~min}$ exposure to the indicated agonist, either without (open bars) or with (striped bars) $500 \mu \mathrm{M} \mathrm{Zn} ; B L A N K$ indicates sham wash control (no agonist). Agonist concentrations were NMDA, $500 \mu \mathrm{M}$; quisqualate $(Q U I S), 30 \mu \mathrm{M}$; and kainate $(K A I N), 1 \mathrm{~mm}$. LDH values were scaled to that produced by $500 \mu \mathrm{M}$ NMDA $(=100)$. A low concentration of quisqualate $(30 \mu \mathrm{M})$ was intentionally chosen to make any potentiating effect more conspicuous; kainate was previously established to be a weak neurotoxin with $5 \mathrm{~min}$ exposure (Koh and Choi, 1988). Zn produced the expected attenuation of NMDA-induced neurotoxicity, but potentiated the neurotoxicity of quisqualate, and, to a lesser extent, kainate; $\mathrm{Zn}$ alone produced little neuronal injury. * Significant difference compared with the agonist-only condition: $p<0.01 ; 2$-tailed $t$ test.

$\mu \mathrm{M} \mathrm{Zn}$ was included in the exposure solution, this glutamateinduced neuronal loss was markedly reduced (Fig. $6 B$ ). Like the protective effect of $\mathrm{Zn}$ on NMDA neurotoxicity, the protective effect of $\mathrm{Zn}$ on glutamate showed a U-shaped $\mathrm{Zn}$ concentration dependence, with maximal protective effect at $300 \mu \mathrm{M}$ (Fig. 7).

Even at $300 \mu \mathrm{M} \mathrm{Zn}$, however, there were still substantial amounts of residual glutamate-induced neuronal injury, in distinction to the near-zero injury seen after the addition of 300 $\mu \mathrm{M} \mathrm{Zn}$ to NMDA (Fig. 1), or to the addition of $1 \mathrm{~mm}$ D-APV to glutamate (Choi et al., 1988). We hypothesized that some of this residual injury reflected the Zn-augmented, non-NMDA receptor-mediated toxicity of glutamate.

To test this hypothesis, we studied the effect of $\mathrm{Zn}$ on the fate of the cortical neuronal subpopulation containing high concentrations of NADPH-d(+) neurons, a marker population shown in the preceding paper to be selectively resistant to NMDAreceptor agonists, and selectively vulnerable to non-NMDAreceptor agonists (Koh and Choi, 1988). Cultures exposed to glutamate showed similar degrees of widespread neuronal loss and NADPH-d(+) neuronal loss (Koh and Choi, 1988). Despite the fact that addition of $300 \mu \mathrm{M} \mathrm{Zn}$ to the glutamate exposure solution markedly attenuated the overall number of neurons destroyed by glutamate, it significantly increased loss of the NADPH-d(+) subpopulation, virtually eliminating these cells from the cultures (Fig. 8) (5 of 5 experiments).

This differential effect of $\mathrm{Zn}$ on the vulnerability of the overall cortical neuronal population and on the NADPH-d(+) subpopulation was not mimicked by several other selective NMDA antagonists: $1.5 \mathrm{~mm}$ APV and $20 \mu \mathrm{M}$ dextrorphan (Church et al., 1985; Choi et al., 1987h) attenuated glutamate neurotoxicity to a greater degree than $300 \mu \mathrm{M} \mathrm{Zn}$, but did not potentiate glutamate-induced NADPH-d(+) neuronal cell loss (Fig. 9).
Zn POTENTIATES QUISQUALATE TOXICITY

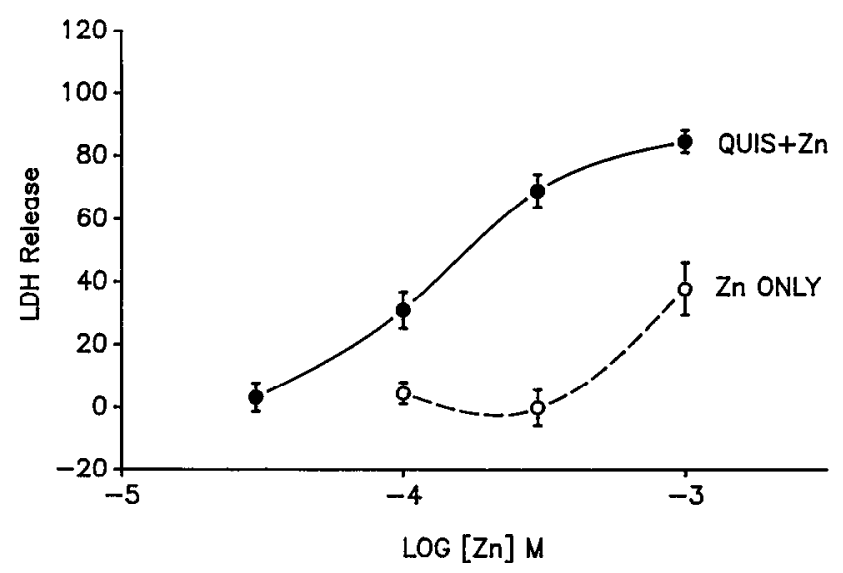

Figure 5. Zn potentiates quisqualate neurotoxicity in a concentrationdependent manner. Matched sister cultures (from the same plating as the cultures used in Fig. 1) were exposed for $5 \mathrm{~min}$ to $10 \mu \mathrm{M}$ quisqualate in the presence of the indicated concentrations of $\mathrm{Zn}$ (closed circles; mean \pm SEM LDH efflux, $n=4$ ), or to $\mathrm{Zn}$ alone (open circles; same data as Fig. 1). As in Figure 1, LDH efflux is scaled to the mean value observed in sister cultures exposed to $500 \mu \mathrm{M}$ NMDA for $5 \min (=100)$.

Magnesium ( $\mathrm{Mg}$ ) (10 mM) produced little effect on either overall glutamate neurotoxicity or glutamate-induced NADPH-d(+) neuronal cell loss (Fig. 9).

\section{Discussion}

The present study quantitatively describes a novel set of interactions between $\mathrm{Zn}$ and the neurotoxicity of EAAs on cortical neurons. At bath concentrations between 30 and $500 \mu \mathrm{M}, \mathrm{Zn}$ selectively attenuated the neurotoxicity of NMDA, while potentiating the neurotoxicity of quisqualate and perhaps also of kainate. These $\mathrm{Zn}$ effects parallel some recently observed effects on EAA neuroexcitation, both in cortical cultures (Peters et al., 1987) and in hippocampal cultures (Westbrook and Mayer, 1987).

The most striking effect of $\mathrm{Zn}$ observed here was attenuation of NMDA neurotoxicity, which occurred with an $\mathrm{ED}_{s 0}$ of approximately $80 \mu \mathrm{M} ; 300 \mu \mathrm{M} \mathrm{Zn}$ virtually eliminated NMDAinduced neuronal cell injury under the present conditions. This blockage occurred in a noncompetitive fashion: unlike the block produced by APV, the Zn block was not overcome by concentrations of NMDA as high as $3 \mathrm{~mm}$.

In contrast, the same concentrations of $\mathrm{Zn}$ potentiated the neurotoxicity of low concentrations of quisqualate. This potentiating effect was most clearly apparent at $\mathrm{Zn}$ concentrations of 100-500 $\mu \mathrm{M}$, which showed little or no intrinsic toxicity with the $5 \mathrm{~min}$ exposures used; $1 \mathrm{~mm} \mathrm{Zn}$ further increased net neuronal injury, but did itself produce injury. The potentiating effect of $\mathrm{Zn}$ was less striking with kainate than with quisqualate: 500 $\mu \mathrm{M} \mathrm{Zn}$ increased quisqualate neurotoxicity more than 10 -fold, but increased kainate neurotoxicity only $2-3$-fold.

As previous observations suggested that glutamate neurotoxicity was predominantly mediated by NMDA receptors (Choi et al., 1988), $\mathrm{Zn}$ also considerably reduccd nct glutamatc ncurotoxicity. Unlike NMDA neurotoxicity, however, glutamate neurotoxicity was not eliminated by even optimal $(300 \mu \mathrm{M}) \mathrm{Zn}$ concentrations: over a third remained. This residual is substantially more than the near-zero residual glutamate neurotoxicity 

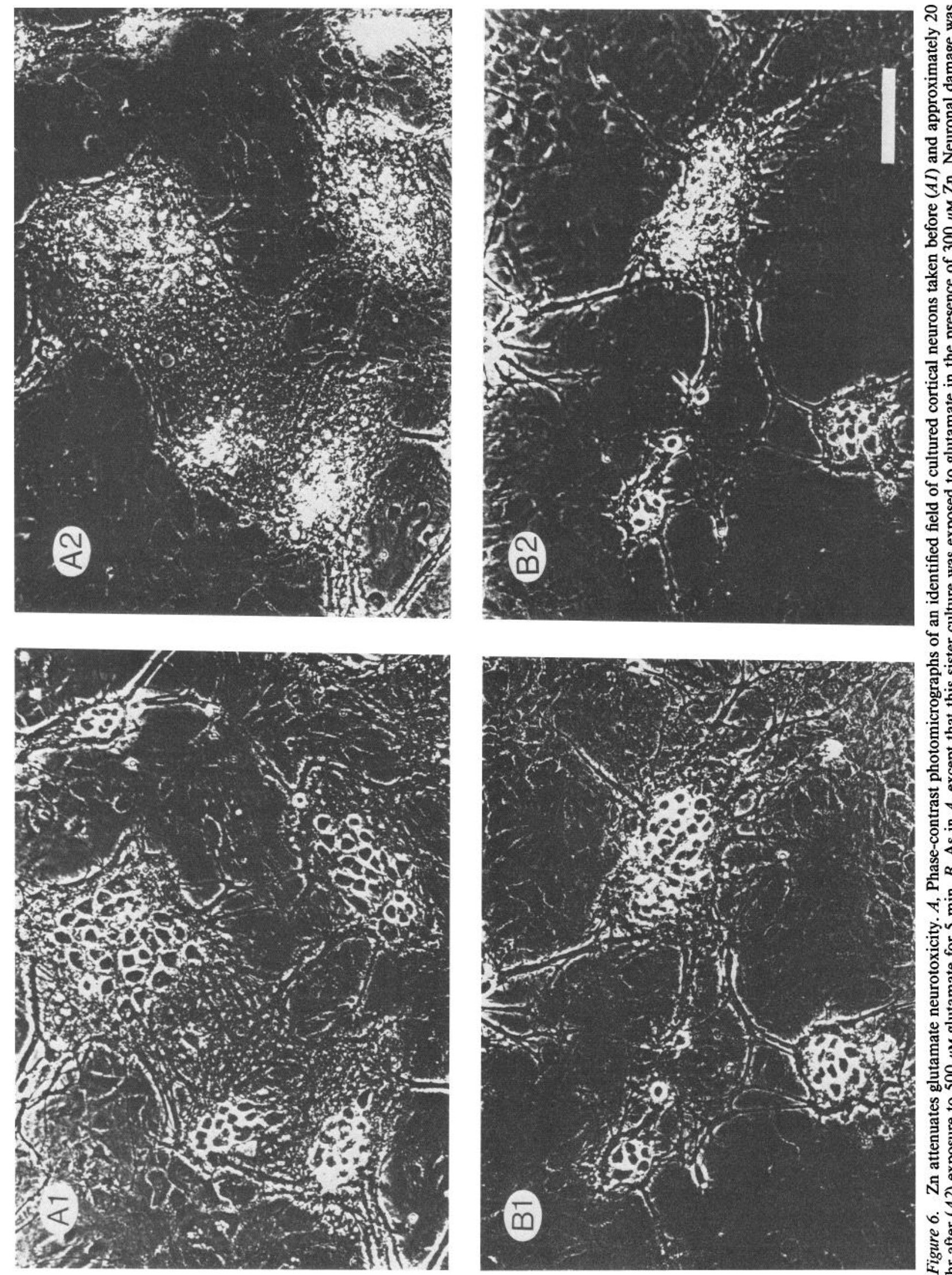

농

负.

․ㅐㅆ을

응

츠

흥

a

龸

.

$\delta$ ज

唔

a

阳要

in

홍후

워

유

행다

ㅡㅐ을

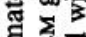

其

콩으 :

¿ㅇㅇㅇ

뜽

突

ลี ิิ

. डิ

는

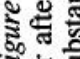

空点 
Zn ATTENUATES GLUTAMATE NEUROTOXICITY

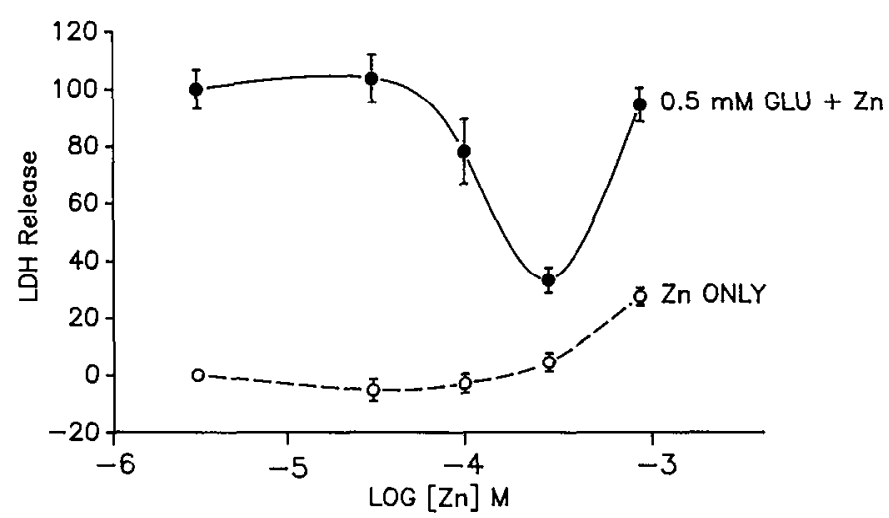

Figure 7. Zn attenuates glutamate neurotoxicity in a concentrationdependent manner. Cultures were exposed to $500 \mu \mathrm{M}$ glutamate for 5 $\mathrm{min}$ in the presence of the indicated concentrations of $\mathrm{Zn}(\mathrm{Glu}+\mathrm{Zn})$; other matched sister cultures were exposed to the $\mathrm{Zn}$ alone ( $\mathrm{Zn}$ only). $\mathrm{LDH}$ in the bathing medium (mean \pm SEM, $n=3$ or 4 ) was measured the following day, and scaled to the mean value of other matched cultures exposed to $500 \mu \mathrm{M}$ glutamate alone. At $300 \mu \mathrm{M}$, Zn substantially antagonizes glutamate neurotoxicity, but at higher concentration ( $1 \mathrm{~mm})$, $\mathrm{Zn}$ exhibits intrinsic toxicity.

left by selective NMDA antagonism with $1 \mathrm{mM}$ D-APV (Choi et al., 1988). It is tempting to postulate that this increased residual reflects potentiation of the normally minimal quisqualate receptor-mediated component of glutamate neurotoxicity.

Supporting this postulate, $\mathrm{Zn}$ paradoxically increased the destruction of the NADPH-d(+) neuronal subpopulation by glutamate, even while simultaneously reducing overall cortical neuronal injury. Since NADPH-d(+) neurons are selectively resistant to NMDA receptor-mediated toxicity, but selectively vulnerable to non-NMDA receptor-mediated toxicity (Koh and Choi, 1988), this selective destruction is consistent with an augmentation of the neurotoxic action of glutamate at non-NMDA receptors. In comparison, the simple NMDA antagonists APV, dextrorphan, and $\mathrm{Mg}$ did not increase glutamate-mediated NADPH-d(+) neuronal loss.

A total of $10 \mathrm{~mm} \mathrm{Mg}$ also failed to produce much reduction in overall glutamate neurotoxicity, an observation previously reported (Choi et al., 1987a) and possibly explained, in part, by the relief of the $\mathrm{Mg}$ block of the NMDA channel by membrane depolarization (e.g., caused by glutamate action on non-NMDA receptors, or by potassium released by other injured neurons) (Mayer et al., 1984; Nowak et al., 1984). Full definition of the as yet unknown nature of the interaction between $\mathrm{Zn}$ and EAA receptor complexes will likely be required in order to understand why $\mathrm{Zn}$ is better than $\mathrm{Mg}$ at attenuating glutamate neurotoxicity. The simple postulate that $\mathrm{Zn}$ is better able to block the NMDA channel, perhaps especially at depolarized membrane potentials, cannot alone account for the ability of $\mathrm{Zn}$ to potentiate both the neuroexcitatory and neurotoxic effects of quisqualate.

The concentrations of $\mathrm{Zn}$ required to alter EAA neurotoxicity in the present experiments may well be attained during high levels of synaptic activity, or in pathological conditions associated with neuronal depolarization. Assaf and Chung (1984) estimated that the $\mathrm{Zn}$ rapidly released by hippocampal slices exposed to $23 \mathrm{~mm} \mathrm{~K}$ could produce a $300 \mu \mathrm{M}$ concentration distributed uniformly throughout extracellular space; any lo-
Zn MODULATES GLUTAMATE NEUROTOXICITY

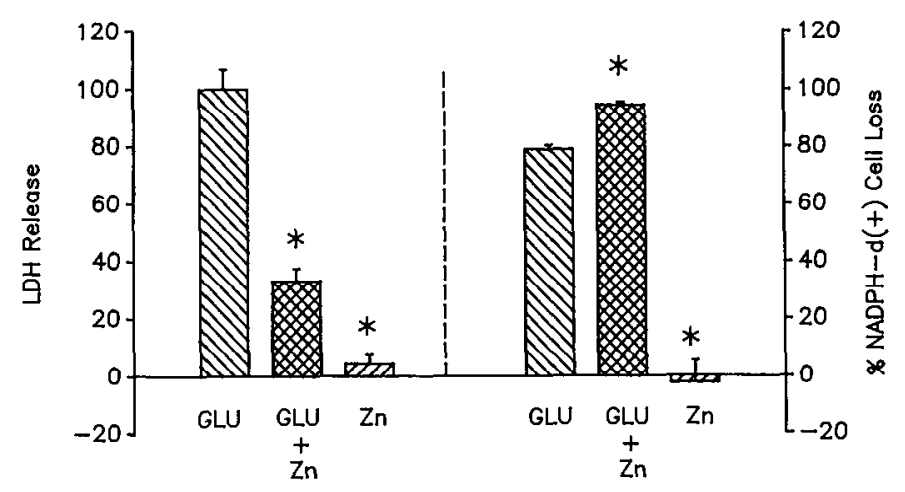

Figure 8. Zn modulates the nature of glutamate neurotoxicity. As can be seen in the left-hand bars (mean \pm SEM LDH efflux, $n=3$ or 4 ), the addition of $300 \mu \mathrm{M} \mathrm{Zn}(\mathrm{Glu}+\mathrm{Zn})$ markedly attenuated the overall neuronal injury produced by $500 \mu \mathrm{M}$ glutamate (Glu), and the same exposure to $\mathrm{Zn}$ alone $(\mathrm{Zn})$ had little toxicity. LDH efflux was scaled to that produced by $500 \mu \mathrm{M}$ glutamate exposure alone $(=100)$.

However, as summarized in the right-hund bars (mean $\pm \mathrm{SEM}, n=$ 3 or 4 ), in the same cultures the addition of $\mathrm{Zn}$ to glutamate (but not $\mathrm{Zn}$ alone) actually increased loss of the NADPH-d(+) neuronal subpopulation. NADPH-d $(+)$ neuronal cell counts were normalized to the number present in wash controls ( $=0 \%$ loss). * Significant difference $(p<0.005)$ compared with glutamate alone $(2$-tailed $t$ test with Bonferroni correction to account for 2 comparisons).

calization to synaptic zones would act to increase this figure. $\mathrm{Zn}$ could act to fundamentally alter the neurotoxicity of endogenously released glutamate, shifting neurotoxic activation away from NMDA receptors toward quisqualate receptors. This shift would produce a generally neuron-protective effect under most

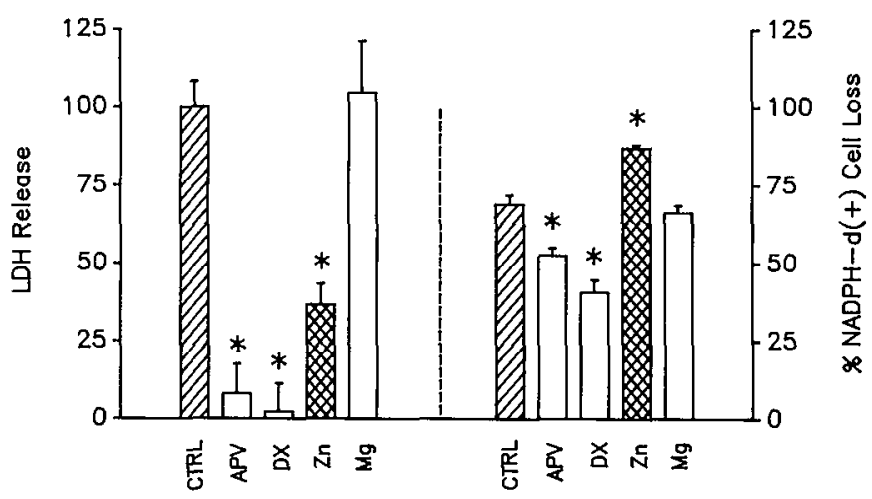

Figure 9. The non-NMDA-potentiating effect of $Z$ n on glutamate neurotoxicity is not produced by other NMDA antagonists. The bars on the left depict mean + SEM LDH efflux produced by 5 min exposure to $500 \mu \mathrm{M}$ glutamate, either alone $(C T R L)$, or in the presence of $1.5 \mathrm{~mm}$ DL-APV $(A P V), 20 \mu \mathrm{M}$ dextrorphan $(D X), 300 \mu \mathrm{M} \mathrm{Zn}(\mathrm{Zn})$, or $10 \mathrm{~mm}$ $\mathrm{Mg}(M g)$. The bars on the right depict the mean + SEM loss of NADPH-d $(+)$ cells in the same cultures, normalized as above to the number of cells present in sham wash controls ( $=0 \%$ loss). Although both APV and dextrorphan mimicked the ability of $\mathrm{Zn}$ to attenuate the general neuronal cell loss produced by glutamate, only $\mathrm{Zn}$ simultaneously increased the loss of the NADPH-d(+) neuronal subpopulation in the same cultures (left-hand bars; mean $+\operatorname{SEM}, n=3$ or 4 ). APV and dextrorphan both slightly attenuated the damage to NADPH-d $(+)$ cells, but to a degree less than expected from their marked overall protective effect. Magnesium had little or no effect on either the general population or the NADPH-d $(+)$ subpopulation. * Significant differences $(p<0.05)$ compared with glutamate alone (2-tailed $t$ test with Bonferroni correction for 4 comparisons). 
conditions. It might be interesting to try to correlate the availability of synaptic $\mathrm{Zn}$ with neuronal vulnerability to injury in various disease states thought to involve NMDA receptormediated neurotoxicity.

However, the present study also indicates that $\mathrm{Zn}$ is potentially a "two-edged sword," capable of selectively increasing EAA-induced injury to certain neurons (e.g., NADPH-d(+) neurons) highly vulnerable to non-NMDA receptor-mediated neurotoxicity. Furthermore, under conditions of extremely intense $\mathrm{Zn}$ release, it is possible that some dircct $\mathrm{Zn}$-induced ncuronal injury (Yokoyama et al., 1987) might occur.

Selective destruction of NADPH-d $(+)$ neurons is used here simply as a putative experimental index of non-NMDA receptor-mediated neurotoxicity, but it could have intrinsic direct relevance to certain disease states. As discussed in the preceding paper (Koh and Choi, 1988), NADPH-d colocalizes in mammalian forebrain with somatostatin (Vincent et al., 1983; Kowall and Ferrante, 1985). It is therefore intriguing that a selective loss of somatostatin-containing neurons has been reported to occur in the hippocampal dentate hilus in rat models of both epilepsy (Sloviter, 1987) and cerebral ischemia (Johansen et al., 1987). The hippocampal dentate hilus is known to have the highest $\mathrm{Zn}$ content in the hippocampus (Frederickson et al., 1983), contained, in large part, in afferent mossy fiber terminals that lose Timm's strain after electrical stimulation (Sloviter, 1985), and which are likely glutamatergic (Crawford and Connor, 1973). The neurotoxicity of glutamate and related endogenous EAAs has been postulated to be responsible for much of the neuronal injury produced by epilepsy and hypoxia/ischemia (Rothman and Olney, 1987), but neither glutamate itself nor aspartate or quinolinate preferentially injures NADPH-d $(+)$ cells (Koh and Choi, 1988). We speculate that a neurotoxic combination of $\mathrm{Zn}$ with glutamate might help account for the observed selective depletion of somatostatin-containing neurons in these conditions.

Somatostatin-containing neurons may also be injured preferentially in the cortex and hippocampus of Alzheimer's disease patients (Davies et al., 1980; Rossor et al., 1980; Morrison et al., 1985; Roberts et al., 1985; Chan-Palay, 1987), and in the cortex of patients with Parkinson's disease associated with Alzheimer-type pathology (Beal et al., 1986). Could this early injury of somatostatin-containing neurons similarly be a clue as to the involvement of glutamate neurotoxicity (Maragos et al., 1987)altered by $\mathrm{Zn}$-in the pathogenesis of Alzheimer's disease?

\section{References}

Aniksztejn, L., G. Charton, and Y. Ben-Ari (1987) Selective release of endogenous zinc from the hippocampal mossy fibers in situ. Brain Res. 404: 58-64.

Assaf, S. Y., and S. H. Chung (1984) Release of endogenous $\mathrm{Zn}^{2+}$ from brain tissue during activity. Nature 308: 734-736.

Beal, M. F., M. F. Mazurek, and J. B. Martin (1986) Somatostatin immunoreactivity is reduced in Parkinson's disease dementia with Alzheimer's changes. Brain Res. 397: 386-388.

Chan-Palay, V. (1987) Somatostatin immunoreactive neurons in the human hippocampus and cortex shown by immunogold/silver intensification on vibratome sections: Coexistence with neuropeptide $Y$ neurons, and effects in Alzheimer-type dementia. J. Comp. Neurol. 260: 201-223.

Charton, G., C. Rovira, Y. Ben-Ari, and V. Leviel (1985) Spontaneous and evoked release of endogenous $\mathrm{Zn}^{2+}$ in the hippocanupal mossy fiber zone of the rat in situ. Exp. Brain Res. 58: 202-205.

Choi, D. W., M. A. Maulucci-Gedde, and A. R. Kriegstein (1987a) Glutamate neurotoxicity in cortical cell culture. J. Neurosci. 7: 357368 .
Choi, D. W., S. Peters, and V. Viseskul (1987b) Dextrorphan and levorphanol selectively block $N$-methyl-D-aspartate receptor-mediated neurotoxicity on cortical neurons. J. Pharmacol. Exp. Therap. 242: 713-720.

Choi, D. W., J. Koh, and S. Peters (1988) Pharmacology of glutamate neurotoxicity in cortical cell culture: Attenuation by NMDA antagonists. J. Neurosci. 8: 185-196.

Church, J., D. Lodge, and S. C. Berry (1985) Differential effects of dextrorphan and levorphanol on the excitation of rat spinal neurons by amino acids. Eur. J. Pharmacol. 111: 185-190.

Crawford, I. L., and J. D. Connor (1973) Localization and release of glutamic acid in relation to the hippocampal mossy fibre pathway. Nature 244: 442-443.

Danscher, G., G. Howell, J. Perez-Clausell, and N. Hertel (1985) The dithizone, Timm's sulphide silver and the selenium methods demonstrate a chelatable pool of zinc in CNS. A proton activation (PIXE) analysis of carbon tetrachloride extracts from rat brains and spinal cords intravitally treated with dithizone. Histochemistry 83: 419422.

Davies, J., A. A. Francis, A. W. Jones, and J. C. Watkins (1981) 2-Amino-5-phosphonovalerate (2APV), a potent and selective antagonist of amino acid-induced and synaptic excitation. Neurosci. Lett. 21: 77-81.

Davies, P., R. Katzman, and R. D. Terry (1980) Reduced somatostatin-like immunoreactivity in cerebral cortex from cases of Alzheimer disease and Alzheimer senile dementia. Nature 288: 279-280.

Donaldson, J., T. St. Pierre, J. L. Minnich, and A. Barbeau (1973) Determination of $\mathrm{Na}^{+}, \mathrm{K}^{4}, \mathrm{Mg}^{2+}, \mathrm{Cu}^{2+}, \mathrm{Zn}^{2+}$, and $\mathrm{Mn}^{2+}$ in rat brain regions. Can. J. Biochem. 51: 87-92.

Frederickson, C. J., W. I. Manton, M. H. Frederickson, G. A. Howell, and M. A. Mallory (1982) Stable-isotope dilution measurement of zinc and lead in rat hippocampus and spinal cord. Brain Res. 246 . 338-341.

Frederickson, C. J., M. A. Klitenick, W. I. Manton, and J. B. Kirkpatrick (1983) Cytoarchitectonic distribution of zinc in the hippocampus of man and the rat. Brain Res. 273: 335-339.

Haug, F. M. S. (1973) Heavy metals in the brain. A light microscope study of the rat with Timm's sulphide silver method. Methodological considerations and cytological and regional staining patterns. Adv. Anat. Embryol. Cell Biol. 47: 1-71.

Howell, G. A., M. G. Welch, and C. J. Frederickson (1984) Stimulation-induced uptake and release of zinc in hippocampal slices. Nature 308: 736-738.

Ibata, Y., and N. J. Otsuka (1969) Electron microscopic demonstration of zinc in the hippocampal formation using Timm's sulfide silver technique. Histochem. Cytochem. 17: 171-175.

Johansen, F. F., J. Zimmer, and N. H. Diemer (1987) Early loss of somatostatin neurons in dentate hilus after cerebral ischemia in the rat precedes CA-1 pyramidal cell loss. Acta Neuropathol. 73: 110114.

Koh, J., and D. W. Choi (1988) Vulncrability of culturcd cortical neurons to damage by excitotoxins: Differential susceptibility of neurons containing NADPH-diaphorase. J. Neurosci. 8: 2153-2163.

Kowall, N. W., and R. J. Ferrante (1985) Characteristics, distribution, and interrelationships of somatostatin, neuropeptide $\mathrm{Y}$, and NADPH diaphorase in human caudate nucleus. Soc. Neurosci. Abstr. 11: 209.

Maragos, W. F., J. T. Greenamyre, J. B. Penney, and A. B. Young (1987) Glutamate dysfunction in Alzheimer's disease: An hypothesis. Trends Neurosci. 10:65-68.

Mayer, M. L., G. L. Westbrook, and P. B. Guthrie (1984) Voltagedependent block by $\mathrm{Mg}^{2+}$ of NMDA responses in spinal cord neurones. Nature 309: 261-263.

Morrison, J. H., J. Rogers, S. Scherr, R. Benoit, and F. E. Bloom (1985) Somatostatin immunoreactivity in neuritic plaques of Alzheimer's patients. Nature 314: 90-92.

Nowak, L., P. Bregestovski, P. Ascher, A. Herbet, and A. Prochiantz (1984) Magnesium gates glutamate-activated channels in mouse central neurones. Nature 307: 462-465.

Olverman, H. J., A. W. Jones, and J. C. Watkins (1984) L-Glutamate has higher aflinity than other amino acids for [3H]-D-AP5 binding sites in rat brain membranes. Nature 307: 460-462.

Perez-Clausell, J., and G. Danscher (1985) Intravesicular localization of zinc in rat telencephalic boutons. A histochemical study. Brain Res. 337: 91-98. 
Perez-Clausell, J., and G. Danscher (1986) Release of zinc sulphide accumulations into synaptic clefts after in vivo injection of sodium sulphide. Brain Res. 362: 358-361.

Peters, S., J. Koh, and D. W. Choi (1987) Zinc selectively blocks the action of $N$-methyl-D-aspartate on cortical neurons. Science 236:589593.

Roberts, G. W., T. J. Crow, and J. M. Polak (1985) Location of neuronal tangles in somatostatin neurones in Alzheimer's disease. Nature 314: 92-94.

Rossor, M. N., P. C. Emson, C. Q. Mountjoy, M. Roth, and L. L. Iversen (1980) Reduced amounts of immunoreactive somatostatin in the temporal cortex in senile dementia of Alzheimer type. Neurosci. Lett. 20: 373-377.

Rothman, S. M., and J. W. Olney (1987) Excitotoxicity and the NMDA receptor. Trends Neurosci. 10: 299-302.

Sloviter, R. S. (1985) A selective loss of hippocampal mossy fiber Timm stain accompanies granule cell seizure activity induced by perforant path stimulation. Brain Res. 330: 150-153.

Sloviter, R. S. (1987) Decreased hippocampal inhibition and a selective loss of interneurons in experimental epilepsy. Science 235: 7376.
Vallee, B. L. (1959) Biochemistry, physiology, and pathology of zinc. Physiol. Rev. 39: 443-490.

Vincent, S. R., O. Johansson, T. Hökfelt, L. Skirboll, R. P. Elde, L. Terenius, J. Kimmel, and M. Goldstein (1983) NADPH-diaphorase: A selective histochemical marker for striatal neurons containing both somatostatin- and avian pancreatic polypeptide (AP)-like immunoreactivities. J. Comp. Neurol. 217: 252-263.

Watkins, J. C., and R. H. Evans (1981) Excitatory amino acid transmitters. Annu. Rev. Pharmacol. Toxicol. 21: 165-204.

Westbrook, G. L., and M. L. Mayer (1987) Micromolar concentrations of $\mathrm{Zn}^{2+}$ antagonize NMDA and GABA responses of hippocampal neurons. Naturc 328: 640-643.

Wong, P. Y., and K. Fritze (1969) Determination by neutron activation of copper, manganese, and zinc in the pineal body and other areas of brain tissue. J. Neurochem. 16: 1231-1234.

Yokoyama, M., J. Koh, and D. W. Choi (1987) Brief exposure to zinc is toxic to cortical neurons. Neurosci. Lett. 71:351-355. 